\title{
Flow mediated vasodilation compared with carotid intima media thickness in the evaluation of early cardiovascular damage in menopausal women and the influence of biological and psychosocial factors
}

Mauricio Sanchez-Barajas ${ }^{1,2}$, Lorena del Rocio Ibarra-Reynoso ${ }^{2}$, Marco Antonio Ayala-Garcia ${ }^{3}$ and Juan Manuel Malacara ${ }^{2 *}$ (D)

\begin{abstract}
Background: Women after menopause increase risk for cardiovascular disease and several factors may be related. The purpose was to study biological and psychosocial factors associated with early cardiovascular damage in preand postmenopausal women, assessed with carotid intima-media thickness vs flow-mediated dilatation.

Methods: Women 45 to 57 years old were grouped in the pre- $(n=60)$, early $(n=58)$ and late post-menopause $(n$ =59). Anthropometric, metabolic and hormonal data were registered, as well as measures of depression, anxiety, submission, perceived stress, and sleep alterations. Heart Rate Variability was recorded to obtain the information regarding sympathovagal balance. Carotid intima-media thickness and flow-mediated dilatation were assessed by ultrasound. Two-way ANOVA and multiple regression model were used.
\end{abstract}

Results: At late postmenopause, the carotid intima-media was thicker $(p<0.001)$ and flow-mediated dilatation decreased $(p<0.001)$. Carotid intima-media thickness was associated positively with age $(p<0.001)$, submission score $(p=0.029)$, follicle stimulating hormone levels $(p<0.001)$, and body mass index $(p=0.009)$. Flow-mediated dilatation was associated only with age $(p<0.001)$. Regarding heart rate variability, the time domain pNN50 measurement was higher in premenopausal women $(p=0.001)$, Low Frequency $(L F)$ was higher in the two groups of postmenopausal ( $p=0.001)$ and High Frequency (HF) higher in the early postmenopausal women $(p=0.042)$.

Conclusions: Under our conditions carotid intima-media thickness had higher predictive value for early cardiovascular damage at menopause. The finding of the association of the submission score, indicates de influence of stress on vascular damage.

Keywords: Menopause, Cardiovascular risk, Flow-mediated vasodilation, Carotid intima media thickness, Heart rate variability, Submission

\footnotetext{
* Correspondence: jmmalacara@hotmail.com

${ }^{2}$ Department of Medical Sciences, University of Guanajuato, León Campus,

León, GTO, Mexico

Full list of author information is available at the end of the article
}

(c) The Author(s). 2018 Open Access This article is distributed under the terms of the Creative Commons Attribution 4.0 International License (http://creativecommons.org/licenses/by/4.0/), which permits unrestricted use, distribution, and reproduction in any medium, provided you give appropriate credit to the original author(s) and the source, provide a link to the Creative Commons license, and indicate if changes were made. The Creative Commons Public Domain Dedication waiver (http://creativecommons.org/publicdomain/zero/1.0/) applies to the data made available in this article, unless otherwise stated. 


\section{Background}

Menopause, the permanent cessation of menstruation results from ovarian senescence with depletion of ovarian follicles and decreased estrogen production [1]. Estrogenic deficiency during the menopausal transition frequently leads to somatic, psychological, and vasomotor symptoms, and sexual dysfunction. Women may suffer depression, anxiety and sleep alterations attributed to low estrogen levels with the interaction of psychosocial conditions [2].

Women, at this period of their life may have hot flashes, also associated with mood alterations that may be related to the influence of psychosocial conditions and the perception of their role in society [3]. Mood alterations like depression [4], and hostility [5] are predictors of mortality and cardiovascular events.

The incidence for cardiovascular diseases (CVDs) sharply increases after 50 years of age, making them the main cause of death in mature women, exceeding all cancer deaths [6].

Increased risk of CVDs, may be related to several physiological changes such as increased body fat [7], and an adverse lipid profile [8]. The vascular endothelium produces autoimmune, endocrine, and paracrine factors [9], of primary importance in vascular function. Endothelial dysfunction is a relevant event in atherogenesis and cardiovascular damage in postmenopausal women [10]. The SWAN study [11] reported that peri- and postmenopausal women had larger diameters of common carotid artery and adventitial than at premenopause, suggesting that estrogen diminution is associated with vascular damage.

Numerous factors alter the endothelial function, such as age [12], dyslipidemia, hypertension, obesity, smoking habit, diabetes mellitus, and psychosocial factors [13].

Carotid intima media thickness (C-IMT) is a widely used surrogate marker of subclinical atherosclerosis with established prognostic value [14]. Assessment of endothelial function using brachial artery flow-mediated dilatation (FMD) is another predictor of cardiovascular events [15], used for risk stratification [10].

Few studies have compared the efficacy of these two clinical measurements in the environment of menopause. Some authors indicate that at premenopause [16] and early menopause [17], the measurement of FMD is a more appropriate test for cardiovascular damage than C-IMT. However, a recent study supports C-IMT as a subclinical marker of vascular damage in postmenopause in the presence of metabolic syndrome [18].

The Heart Rate Variability (HRV) is an index of sympathovagal balance, which is altered in relation to mood disorders and cardiovascular risk [19]. HRV is negatively associated with C-IMT and its progression [20]. The sympathovagal tonus during the stress test is negatively correlated with C-IMT [20]. In a previous study, we found associated HRV and ultrasonographic carotid indices (resistive index, young's elastic modulus, arterial compliance, arterial distensibility) in peri- and postmenopausal women [21], indicating a manifestation of autonomic imbalance and cardiovascular risk.

Considering the need for a reliable clinical evaluation of early cardiovascular risk, we studied biological and psychosocial factors associated with early cardiovascular damage in pre- and postmenopausal women, assessed with carotid intima-media thickness as a measure of subclinical atherosclerosis vs flow-mediated dilatation as a measure of endothelial function.

\section{Methods}

\section{Study population}

We carried out a descriptive, comparative study in 177 women invited at their home in urban and suburban areas of León, Mexico.

We included women hysterectomized, non-pregnant, non-lactating, without clinical evidence of acute or chronic, infectious, metabolic or cardiovascular disease. They did not have history of recent anxiolytics, antidepressants, analgesics, vitamins, or antibiotic consumption. They did not receive previously hormone replacement therapy.

We compared three groups according to menopausal stage, according STRAW criteria [22]. Women at pre-menopause, with regular menstrual periods $(n=60)$; at early postmenopause, women aged 45 to 57 and less than 5 years since the last menstrual $(n=58)$. Women older to 57 and with more than 5 years since the last menstrual period were classified at late postmenopause $(n=59)$.

This study was approved by the Committee of Bioethics of the University of Guanajuato. Eligible participants who accepted inclusion signed informed consent.

\section{Anthropometry data and body composition}

We collected age, height, weight, and waist circumference. Body mass index (BMI) was calculated $\left(\mathrm{kg} / \mathrm{m}^{2}\right)$. Waist circumference was measured at the middle between the lower rib and the iliac crest.

\section{Data collection}

We collected years of schooling, work as housewife or out of home, exercises at least 1 day/week (yes or no), smoking habit (yes or no), and alcohol consumption (at least one drink/week, yes or no), as described in our previous studies [20,21]. Blood pressure was measured with a random zero sphygmomanometer in sitting position after a five minutes rest. 


\section{Gyneco-obstetric history}

The age at menarche, date of the last menstrual period, number of pregnancies, deliveries, abortions, cesarean sections and complications during pregnancy were also registered.

\section{Physical and psychological symptoms}

Women answered a questionnaire on physical and psychological symptoms at menopause, as in our previous works [21, 23], to assess: hot flushes as sensations of transient heat in skin, sexual interest (yes or not), perceived stress, anxiety, depressive mood, sleep disturbances, submission and effort/reward imbalance.

We reported intensity of hot flushes as none $=0$, slight $=$ 1 , moderate $=2$, or severe $=3$. Depressive mood and anxiety were evaluated with the Hamilton-Bech-Raphaelsen Scale [24]. Depressive mood was rated 0 to 4 , with total scores ranging 0 to 26 . The anxiety score is an 18-item self-reported questionnaire ranging from 0 to 18 .

Perceived stress was measured using an instrument adapted from Cohen as us in previous reports [25, 26], with 14 questions and a score of 0 to 56 .

For the effort-reward imbalance (ERI) evaluation, we used the instrument of Siegrist [27] adapted to the Spanish language [28]. This scale results from the ratio of extrinsic effort/reward, both factors collected with a Likert scale (1 to 5$)$. Values above or below 1.0, indicate high or low risk, respectively. For submission score we used a modified Rathus Assertiveness Scaling [29], which contain 16 items, and a score ranging from 0 to 64 . The evaluation of sleep was recorded in two items: difficulties sleeping and sleep disturbances, in three levels, with a total score of 0 to 6 .

\section{Samples and laboratory procedures Samples}

Samples of peripheral blood were drawn after 12-h fasting. Serum was stored at $-80^{\circ} \mathrm{C}$ until use.

\section{Biochemical determinations}

The concentrations of glucose, creatinine and lipid profile were determined by enzymatic colorimetric methods with precisions of $1.5 \%, 2.2 \%$ and $2.1 \%$ respectively.

\section{Quantification of hormones}

We quantified cortisol serum levels as biomarker of stress response. Follicle stimulating hormone (FSH) and serum morning cortisol were measured by ELISA commercial kits (ALPCO, USA), with respective intra- and interassay coefficients of variation of $3.4 \%$ and $7.7 \%$ for FSH and $2.9 \%$ and $3.8 \%$ for cortisol.

\section{Heart rate variability}

According to the consensus Task Force of the European Society of Cardiology and the American Society of Electrophysiology [30], two periods for recording have been validated, at $5 \mathrm{~min}$ and $24 \mathrm{~h}$. Recording was carried out in a fasting condition after ten minutes rest. The RS800CX clock (Polar, Finland) was used from 8:00 a.m. to 12:00 p.m. Smoking or alcohol beverages were not allowed for one day before study. During the hours of recording women realized the normal activities. The use of this instrument was validated as a convenient and inexpensive device for a reliable assessment of HRV (18).

The Time Domains studied were: SDNN (Standard deviation of NN intervals in milliseconds) $141 \pm 39$ : reflecting the influence of the sympathetic system. $r M S S D$ (Square root of the mean squared differences of adjacent intervals in milliseconds) $27 \pm 12$ : indicates the vagal influence on HRV. pNN50 (The proportion of adjacent normal RR intervals differing more than $50 \mathrm{~ms}$ ) 2-5\%: A decrease in its normal value indicates cardiovascular risk, with parasympathetic influence.

Frequency Domains determined were: HF (High frequency) $0.04-0.15 \mathrm{~Hz}$ : is known to reflect mainly the effect mediated parasympathetic vagal tone. LF (Low frequency) 0.15 to $0.40 \mathrm{~Hz}$ : evaluates both sympathetic and parasympathetic inputs and has been associated to the role of baroreceptors. $L F / H F$ index $1.5-2 \%$ : is considered as an indicator of the sympathetic-parasympathetic imbalance.

Power spectral measurements were calculated according to the autoregressive model with an order size of 16 . The spectral power of each frequency is expressed in absolute values $(\mathrm{ms} 2 / \mathrm{Hz})$, with logarithmic transformation. Statistical analysis was carried out using the MATLAB ${ }^{\circ}$ (The Math Works USA) [31] software, based on Fourier transformation [32-34].

\section{Assessment of early cardiovascular damage}

The early cardiovascular damage was assessed with carotid intima-media thickness as a measure of subclinical atherosclerosis vs flow-mediated dilatation as a measure of endothelial function. For both tests, we used continuous variables, considering that provide more information than the use of cut-off points.

The assessment of endothelial function on the brachial artery flow-mediated dilatation was made with a high-resolution ultrasound Doppler according to the recommended guidelines of the American College of Cardiologists [35]. The test was carried out in our facilities at 8:00 am in a quiet, temperature-controlled room. In order to minimize the impact of short term hormonal changes, those measurements were made in the first seven days of the menstrual cycle in premenopausal women. Participants were asked to sleep a minimum of 
six hours, and not to consume caffeine beverages. The brachial artery flow-mediated dilatation was assessed by external B-mode ultrasound imaging $2-3 \mathrm{~cm}$ above the elbow (Acuson, 7.0 MHz linear transducer; Mountain View, CA, USA) according to the recommendations of the International Brachial Artery Task Force [35, 36]. Depths and gain settings were optimized to identify the lumen to vessel wall interface. The subject rested in the supine position for at least $30 \mathrm{~min}$ before the first scan and remained supine during the evaluation. Blood flow increase was induced by inflation of a pneumatic cuff placed around the forearm to a pressure at least $50 \mathrm{mmHg}$ above systolic blood pressure. Five minutes later the cuff was rapidly deflated. The artery was scanned continuously for $90 \mathrm{~s}$ and recorded on a super-video home system tape for posterior analysis. The diameter of the brachial artery proximal to the elbow was manually measured at the peak of the R-wave at baseline and at 30, 60 and $90 \mathrm{~s}$ following cuff deflation just proximal to the elbow. FMD was defined as the maximal brachial artery diameter recorded between 30 and $90 \mathrm{~s}$ following cuff release minus the diameter at rest and divided by the diameter at rest (\% FMD $=($ post-ischemia diameter - basal diameter $) /$ basal diameter $\times 100)[35]$.

For the assessment of subclinical atherosclerosis, the carotid intima-media thickness was measured with 8.0 $\mathrm{MHz}$ linear transducer, in accordance to the consensus of the American Society of Echocardiography [37]. The average C-IMT was measured in the far wall of the distal third of both primitive carotid arteries. The C-IMT was defined as the segment between the edge blood-intima and media adventitia. The patient in supine or semi-supine position with the head in slight hyperextension and $45^{\circ}$ contralateral rotation was studied as recommended by the consensus of Mannheim in 2007 [38].The image is centered on the back wall of each common carotid artery, a $1 \mathrm{~cm}$ segment proximal to the carotid bifurcation of each side.

Only the intimate (echogenic line) and the media (hypoechoic line) are included in the measurement, based on the manual movement of a cursor at three different points. The average of the three values was used for analysis [38]. Both the C-IMT and FMD measurements were performed by an expert in ultrasonography with a precision of $1.9 \%$ and $1.4 \%$ respectively.

\section{Statistical analyses}

The data are reported as mean and standard deviation or percentage, as appropriate. Normality was assessed using the Kolmogorov-Smirnov test. Data from premenopausal and early and late postmenopausal women were compared using two-way ANOVA for independent variables. We carried out a multiple regression models taking as dependent variables C-IMT and FMD and as regressor candidates: age, BMI, mean arterial pressure, FSH, cortisol, high density lipoprotein (HDL-Cholesterol), Non HDL-Cholesterol, LF, HF, as well as the depression, anxiety, stress and submission scores. We carried out one model including all candidate regressors; considering the strong influence of age, we repeated the procedure excluding age. Then we did the of Bonferroni correction for multiple comparisons.

\section{Results}

The general characteristic of women at premenopause, early and -late postmenopause are shown in Table 1. Women at premenopause had higher schooling, lower parity and marginally lower BMI; waist circumference and mean arterial pressure were not different.

In regards to symptoms, the loss of sexual interest increases with the progression of menopause $(p<0.001)$. The scores of intensity of hot flashes $(p<0.001)$, sleep disruption $(p=0.01)$ and submission $(p=0.006)$ are higher in postmenopausal women.

In the analysis of metabolic data, we found mean glucose level higher in postmenopausal women $(\mathrm{p}=0.006)$. The triglyceride levels, and HDL-Cholesterol were higher at postmenopause $(p=0.009$, and $p<0.001$ respectively). Non HDL-Cholesterol was higher only in late postmenopause group ( $\mathrm{p}<0.001)$.

As expected FSH levels increased at postmenopause $(\mathrm{p}<0.001)$, but cortisol had similar levels in the three groups.

The analysis of heart rate variability showed that the time domain pNN50 was higher in the group at premenopause compared with two groups at postmenopause ( $p=$ 0.001). For frequency domains, LF was higher in the two groups of postmenopausal women $(\mathrm{p}=0.001)$ and $\mathrm{HF}$ higher at early postmenopause $(p=0.042)$. The rest of the variables were not different among the groups. C-IMT, increases progressively at early and late post-menopause $(p$ $<0.001)$. We found that flow-mediated vasodilatation of the brachial artery had lower values in both groups of women at post-menopause $(p<0.001)$.

A multiple regression model was constructed in order to define the factors associated of C-IMT and FMD testing factors representing age, obesity, estrogen deficiency, metabolic and hormonal variables, and depression, anxiety, stress, and submission scores, as well as heart rate variability. In the analysis of C-IMT we found that after Bonferroni correction, only age was positively associated $(p<0.001)$. Taking in consideration that variability of age also includes other factors that change with time, in a second model we removed age, and found FSH, BMI and submission scores positively associated to C-IMT ( $p$ $<0.001, p=0.009$ and $p=0.029$ ). (Table 2 and Fig. 1). 
Table 1 Comparison of characteristics of premenopausal and early and late postmenopausal women

\begin{tabular}{|c|c|c|c|c|}
\hline & $\begin{array}{l}\text { Premenopause } \\
\text { women } \\
(n=60)\end{array}$ & \begin{tabular}{l}
\multicolumn{1}{c}{ Early } \\
postmenopause \\
$(n=58)$
\end{tabular} & \begin{tabular}{l}
\multicolumn{1}{c}{ Late } \\
postmenopause \\
$(n=59)$
\end{tabular} & $p$ \\
\hline Age(years) & $41.4 \pm 5.9$ & $52.5 \pm 4.1$ & $57.7 \pm 4.7$ & $<0.001^{a, b, c}$ \\
\hline Schooling(years) & $11.08 \pm 3.7$ & $7.3 \pm 4.6$ & $8.08 \pm 4.6$ & $<0.001^{\mathrm{a}, \mathrm{b}}$ \\
\hline Parity(number) & $2.4 \pm 1.8$ & $4.3 \pm 2.06$ & $3.8 \pm 2.2$ & $<0.001^{\mathrm{a}, \mathrm{b}}$ \\
\hline Body Mass Index $\left(\mathrm{kg} / \mathrm{m}^{2}\right)$ & $27.3 \pm 4.3$ & $29.3 \pm 5.1$ & $28.7 \pm 4.3$ & 0.061 \\
\hline Waist circumference $(\mathrm{cm})$ & $91.1 \pm 10.5$ & $93.6 \pm 11.8$ & $91.1 \pm 11.1$ & 0.402 \\
\hline Mean arterial pressure $(\mathrm{mmHg})$ & $82.16 \pm 5.30$ & $84.13 \pm 5.38$ & $82.99 \pm 5.89$ & 0.151 \\
\hline Loss of sexual interest(range $0-3$ ) & $0.73 \pm 0.7$ & $1.62 \pm 1.1$ & $1.77 \pm 1.1$ & $<0.001^{\mathrm{a}, \mathrm{b}, \mathrm{c}}$ \\
\hline Intensity of hot flushes $(1-3)$ & $0.23 \pm 0.4$ & $0.86 \pm 0.3$ & $0.74 \pm 0.4$ & $<0.001^{\mathrm{a}, \mathrm{b}}$ \\
\hline Perceived stress(range 0-64) & $24.4 \pm 5.8$ & $22.4 \pm 5.3$ & $25.05 \pm 6.3$ & $0.043^{c}$ \\
\hline Anxiety(range 0-18) & $4.7 \pm 3.03$ & $6.1 \pm 3.8$ & $5.7 \pm 3.6$ & 0.062 \\
\hline Depressive mood(range 0-26) & $5.05 \pm 4.3$ & $5.4 \pm 5.1$ & $5.3 \pm 4.4$ & 0.871 \\
\hline Disturbed sleep(range 0-3) & $0.26 \pm 0.4$ & $0.43 \pm 0.4$ & $0.52 \pm 0.5$ & $0.012^{\mathrm{a}, \mathrm{b}}$ \\
\hline Submission(range 0-64) & $18.4 \pm 9.9$ & $24.2 \pm 11.6$ & $22.9 \pm 9.2$ & $0.006^{\mathrm{a}, \mathrm{b}}$ \\
\hline Effort-reward imbalance & $0.3 \pm 0.1$ & $0.4 \pm 0.5$ & $0.3 \pm 0.1$ & 0.411 \\
\hline Glucose(mg/dl) & $87.5 \pm 9.8$ & $92.6 \pm 10.2$ & $93.05 \pm 11.1$ & $0.006^{\mathrm{a}, \mathrm{b}}$ \\
\hline Triglycerides(mg/dL) & $122.3 \pm 57.7$ & $148.6 \pm 60.1$ & $155.8 \pm 68.8$ & $0.009^{a, b}$ \\
\hline HDL-Cholesterol(mg/dL) & $47.7 \pm 11.7$ & $55.6 \pm 12.01$ & $59.6 \pm 9.5$ & $<0.001^{\mathrm{a}, \mathrm{b}}$ \\
\hline Non HDL-Cholesterol(mg/dL) & $103.6 \pm 31.2$ & $103.2 \pm 27.8$ & $126.1 \pm 34.1$ & $<0.001^{\mathrm{b}, \mathrm{c}}$ \\
\hline $\operatorname{Cortisol}(\mu \mathrm{g} / \mathrm{dL})$ & $10.7 \pm 4.8$ & $12.4 \pm 3.91$ & $13.4 \pm 5.8$ & 0.181 \\
\hline FSH(IU/L) & $12.1 \pm 20.09$ & $49.3 \pm 24.7$ & $53.4 \pm 21.3$ & $<0.001^{\mathrm{a}, \mathrm{b}}$ \\
\hline $\mathrm{SDNN}(\mathrm{ms})$ & $100.6 \pm 80.2$ & $108.9 \pm 74.2$ & $90.3 \pm 44.03$ & 0.362 \\
\hline $\mathrm{rMSSD}(\mathrm{ms})$ & $28.6 \pm 11.0$ & $22.5 \pm 8.5$ & $27.2 \pm 12.6$ & $0.007^{\mathrm{a}, \mathrm{c}}$ \\
\hline pNN50(ms) & $4.3 \pm 6.2$ & $1.6 \pm 1.7$ & $2.4 \pm 2.5$ & $0.001^{a, b}$ \\
\hline $\mathrm{LF}(\mathrm{Hz})$ & $0.02 \pm 0.01$ & $0.04 \pm 0.02$ & $0.03 \pm 0.01$ & $0.001^{a, b}$ \\
\hline $\mathrm{HF}(\mathrm{Hz})$ & $0.06 \pm 0.02$ & $0.09 \pm 0.09$ & $0.08 \pm 0.06$ & $0.042^{\mathrm{a}}$ \\
\hline$L F / H F(H z)$ & $0.5 \pm 0.2$ & $0.5 \pm 0.2$ & $0.5 \pm 0.3$ & 0.702 \\
\hline C-IMT(mm) & $0.59 \pm 0.1$ & $0.71 \pm 0.1$ & $0.77 \pm 0.1$ & $<0.001^{a, b, c}$ \\
\hline Flow-mediated dilatation(\%) & $15.4 \pm 10.2$ & $10.8 \pm 6.7$ & $9.9 \pm 6.3$ & $<0.001^{a, b}$ \\
\hline
\end{tabular}

Data are shown as mean \pm SD; high-density lipoprotein (HDL); FSH (Follicle stimulating hormone); SDNN (Standard deviation of NN intervals); rMSSD (Square root of the mean squared differences of adjacent intervals in milliseconds); pNN50 (The proportion of adjacent normal RR intervals differing more than 50 ms); LF (low frequency); HF (high frequency); C-IMT (intima -media thickness)

a (Premenopause Vs Early postmenopause)

b (Premenopause Vs Late postmenopause)

c (Early vs late postmenopause)

Table 2 Factors associated with intima-media thickness

\begin{tabular}{|c|c|c|c|c|}
\hline $\begin{array}{l}\text { Dependent Variable: C-IMT } \\
\text { MODEL I (Adjusted R2: 0.42) }\end{array}$ & Beta \pm SE & t & p & $p$ after Bonferroni correction \\
\hline Age & $0.55 \pm 0.05$ & 9.31 & $<0.001$ & $<0.001$ \\
\hline Submission score & $0.15 \pm 0.06$ & 2.49 & 0.013 & 0.131 \\
\hline Body mass index & $0.12 \pm 0.06$ & 2.04 & 0.042 & 0.421 \\
\hline \multicolumn{5}{|c|}{ MODEL II* (Adjusted $R^{2}: 0.26$ ) Excluding age from candidate regressors } \\
\hline FSH & $0.31 \pm 0.06$ & 4.73 & $<0.001$ & $<0.001$ \\
\hline Body mass index & $0.22 \pm 0.06$ & 3.32 & $<0.001$ & 0.009 \\
\hline Submission score & $0.20 \pm 0.06$ & 2.98 & 0.003 & 0.029 \\
\hline Non HDL-Cholesterol & $0.18 \pm 0.06$ & 2.75 & 0.006 & 0.059 \\
\hline
\end{tabular}

SE (standard error); C-IMT (intima -media thickness; Non high-density-lipoprotein-cholesterol (Non HDL- Cholesterol); FSH (Follicle stimulating hormone), $\mathrm{p}<0.05$ 


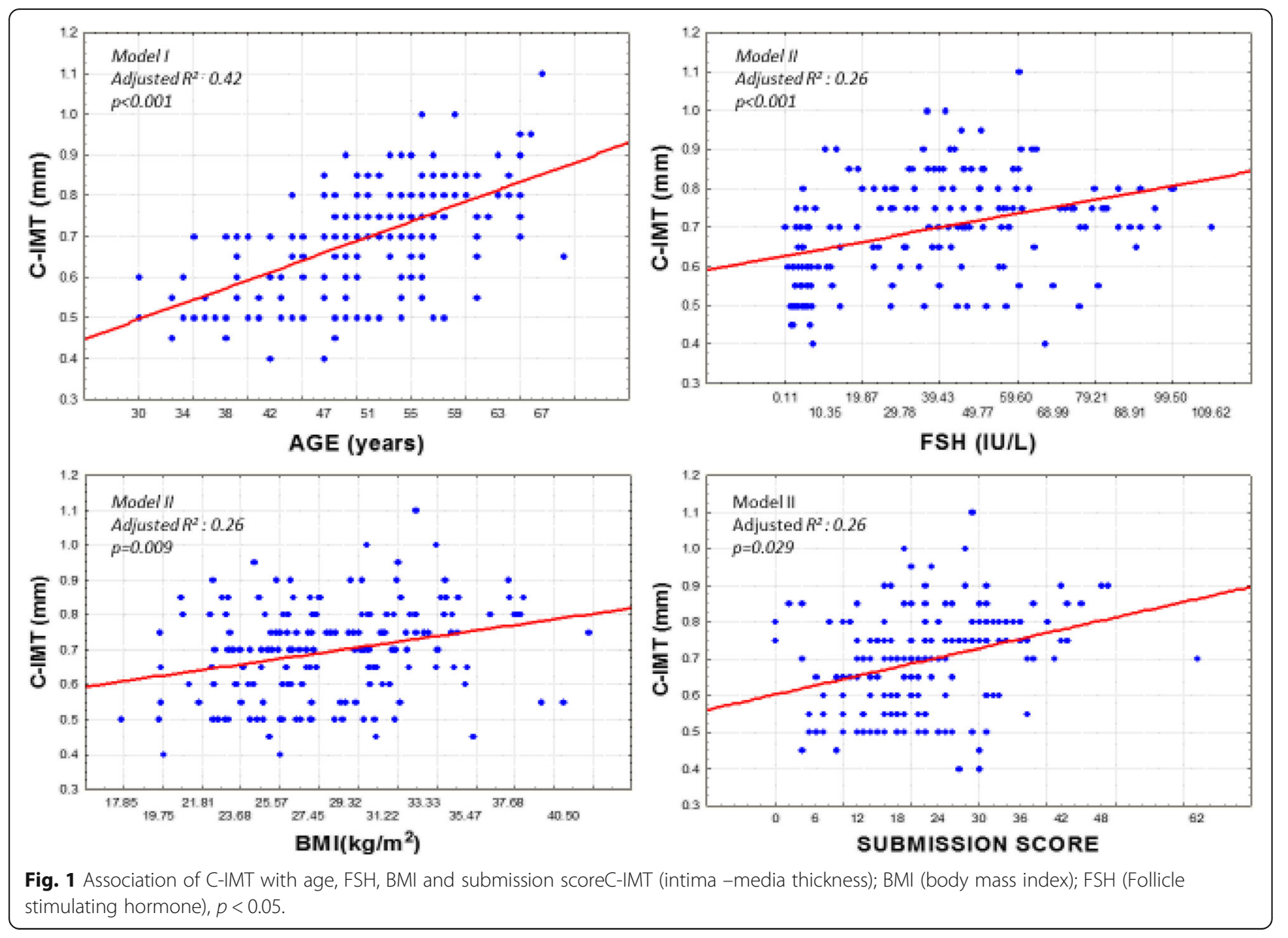

Next, we analyzed the factors associated with FMD. Considering a departure from normality of the variable we carried out analysis after log transformation and found that only age was associated (negatively, $p<$ 0.001), (Table 3 and Fig. 2). In a second model removing age, no variable was significant.

The time since menopause was tested in all the multiple regression models, however the inclusion of this factor did not modify the final model.
Finally, we analyzed the association between FMD and C-IMT, and found them strongly associated $(\mathrm{p}<0.001)$ as shown in Fig. 3.

\section{Discussion}

Women after menopause undergo increased risk for atherosclerotic coronary artery disease [39, 40]. This process has been attributed to the decrease of endogenous estrogen on the cardiovascular system. The

Table 3 Factors associated with Flow-mediated dilatation

\begin{tabular}{|c|c|c|c|c|}
\hline $\begin{array}{l}\text { Dependent variable: Log FMD MODEL I (Adjusted } R^{2}= \\
\text { 0.14) }\end{array}$ & Beta \pm S.E. & $\mathrm{t}$ & $p$ & $\begin{array}{l}P \text { after Bonferroni } \\
\text { correction }\end{array}$ \\
\hline Age & $-0.30 \pm 0.07$ & -4.21 & $\begin{array}{l}\dot{<} \\
0.001\end{array}$ & $<0.001$ \\
\hline Submission score & $-0.19 \pm 0.07$ & -2.75 & 0.006 & 0.078 \\
\hline \multicolumn{5}{|l|}{$\begin{array}{l}\text { MODEL } \|^{*} \text { (Adjusted } R^{2}: 0.12 \text { ) Excluding age } \\
\text { from candidate regressors }\end{array}$} \\
\hline Submission score & $-0.19 \pm 0.07$ & -2.69 & 0.008 & 0.069 \\
\hline HDL-Cholesterol & $-0.18 \pm 0.07$ & -2.59 & 0.010 & 0.093 \\
\hline Non HDL-Cholesterol & $-0.16 \pm 0.07$ & -2.35 & 0.019 & 0.171 \\
\hline Body mass index & $-0.17 \pm 0.07$ & -2.29 & 0.023 & 0.207 \\
\hline
\end{tabular}

SE (standard error); FMD (Flow-mediated dilatation); Non high-density-lipoprotein-cholesterol (Non HDL- Cholesterol), high-density-lipoprotein-cholesterol (HDL-Cholesterol), $\mathrm{p}<0.05$ 


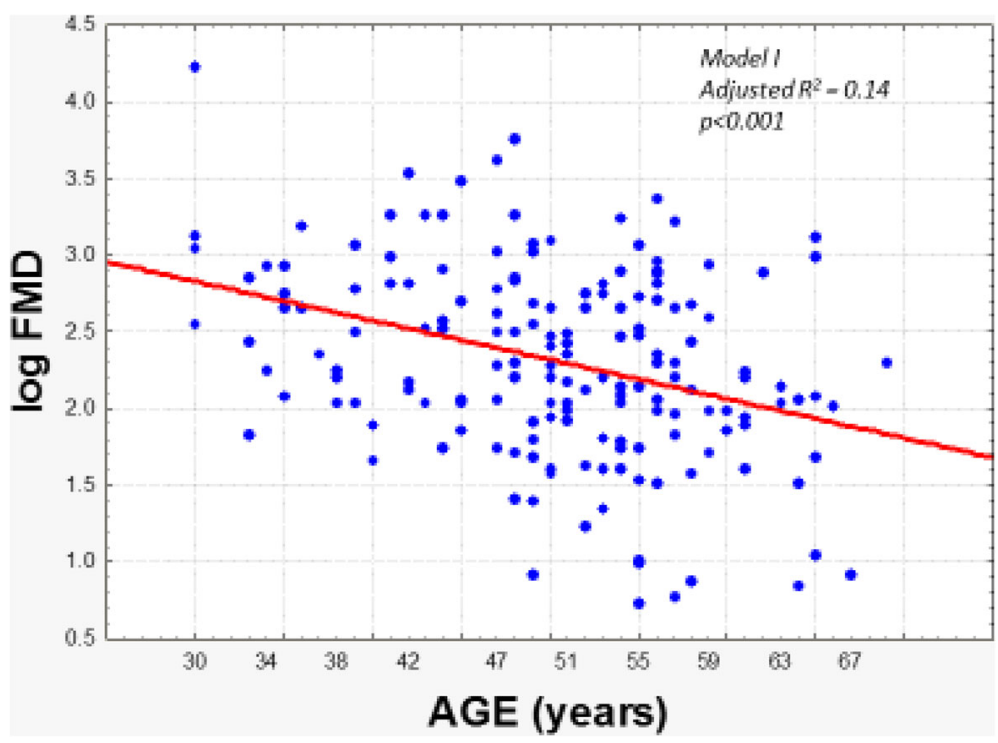

Fig. 2 Association of the Flow-mediated dilatation with ageFMD (flow-mediated dilatation), $p<0.05$.

progression of the effects of estrogen deficiency is indicated by the increase of FSH. The endothelium plays an important role in cardiovascular protection, the vascular tone, as well as in coagulation and inflammatory response [41].

In this work, we found at post-menopause adverse metabolic conditions: higher triglyceride, glucose and non-HDL-cholesterol. However, HDL-cholesterol increased, a factor considered favorable against vascular damage. We found also at post-menopause increased scores related to mood and psychosocial indicators such as disturbed sleep and submission, related to stressful conditions. In regards to $\mathrm{HRV}$, higher time domain pNN50 and lower LF were found at pre-menopause indicating higher sympathetic tone. These findings are representative of conditions that regularly occur in women at these stages of life and agree with previous information [42].

In our study the progressive increase of C-IMT, and decrease in FMD, indicate vascular damage. We are not aware of studies comparing the values of FMD and C-IMT in the three stages of menopause. The high correlation of results

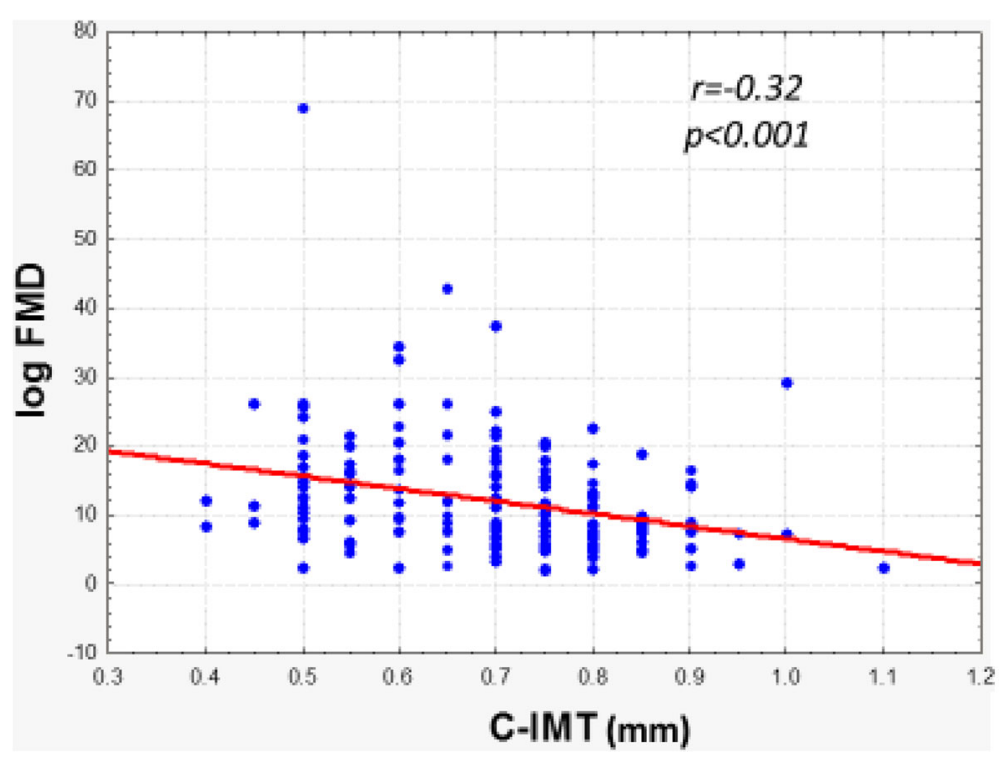

Fig. 3 Association of the Flow-mediated dilatation with intima-media thicknessFMD (flow-mediated dilatation); C-IMT (intima -media thickness), $p<0.05$. 
between these studies supports their value for evaluation of early cardiovascular damage.

In this work, the stronger factor associated with both indicators of early cardiovascular damage was age. However, the correlation was higher for C-IMT than for $\log (\mathrm{FMD})$, with $\mathrm{R}^{2}$ values of 0.42 vs 0.14 respectively. We interpreted this to mean that C-IMT is a better predictor of early cardiovascular damage. We considered that the variance explained by age includes the variance related to the influence of diverse factors related to vascular deterioration. Therefore, in order to disclose the effect of other factors, we repeated the multiple regression models excluding age as candidate regressor. Model II for C-IMT showed the significant association of FSH, $\mathrm{BMI}$, and the submission score. Being FSH an indicator of estrogen diminution, we interpreted these associations to indicate that higher FSH values reflecting the diminished effect of the extensively discussed protective effect on estrogens on vascular damage [43]. Estrogen deficiency induces not only atherogenic lipid abnormalities, but also permit procoagulant oxidative mechanisms and endothelial dysfunction [44]. Previous studies show that estrogen deficiency in premenopausal women with amenorrhea, leads to decreased FMD [45]. The postmenopausal status is associated with higher C-IMT, and with an unstable plaque. It is still unclear whether different menopause stages have an effect on C-IMT differentially. Bechlioulis et al. [17] showed no differences in the C-IMT between early menopause and perimenopause. In our study the C-IMT increases from pre-menopause to early and late post-menopause, which may indicate the continued effect of estrogen deprivation and other damaging factors on the endothelium [46].

Previous studies have also shown correlations between BMI and increased C-IMT [47-49]. Obesity is an important factor for carotid atherosclerosis [50]. In addition to BMI, altered body-fat distribution and ectopic fat deposition are strongly associated with mortality and morbidity attributable to CVDs.

The influence of stress and psychosocial factors on cardiovascular damage has been proposed since long time. A study with female monkeys reported that the subordinate social status correlated with coronary artery atherosclerosis [51], however it has been difficult to prove in humans. Our group have studied various indicators of stress such as the perception of stress, depression, anxiety, dominance and submission dimensions, as well as cortisol measurement. In this work, the submission score was significantly associated with C-IMT. In a previous work, we reported the submission score positively associated with depression, perceived stress, anxiety and hot flashes in post-menopausal women (3). We consider that this is an interesting finding because in modern and traditional societies mature women are labile to the stress induced by insufficient opportunities for a satisfactory role in society. Another data of psychosocial interaction with biological influences, is the correlation of dominance scores with the estrogen receptor polymorphisms [3].

A recent research on FMD and C-IMT in postmenopausal women, reported that C-IMT was associated with metabolic syndrome at this stage [51]. The association of non-HDL-Cholesterol with C-IMT is congruent with the effect of dyslipidemia on vascular damage, as a permissive of atherosclerosis, and stimulation of monocyte infiltration and migration [18]. The increase in HDL-Cholesterol at post-menopause is contrary to previous information [52], but consistent with other reports [53].

The FMD and C-IMT are two inverse indicators of subclinical cardiovascular disease, used for cardiovascular risk stratification. In our conditions, C-IMT was associated with more factors, in a model with higher correlations coefficients, which we interpreted to support a higher predictive value.

A limitation of our study is its cross-section design in which association is deduced only on statistical basis without temporal precedence. Another limitation for more defined effects is that we did not measure biochemical indicators of endothelial dysfunction.

\section{Conclusion}

In conclusion, in menopause the early of cardiovascular damage, can be assessed mainly by C-IMT measurement. The higher submission scores associated with increased C-IMT may be an interesting point about socioeconomic conditions that deserve further investigation of early cardiovascular damage in women during menopause.

\section{Abbreviations}

BMI: Body mass index; C-IMT: Carotid intima media thickness;

CVDs: Cardiovascular diseases; ERI: Effort-reward imbalance; FMD: Flowmediated dilatation; FSH: Follicle stimulating hormone; HDL-Cholesterol: High density lipoprotein; HF: High frequency; HRV: The heart Rate Variability; LF: Low frequency; pNN50: The proportion of adjacent normal RR intervals differing more than 50 ms; rMSSD: Square root of the mean squared differences of adjacent intervals; SDNN: Standard deviation of NN intervals.

\section{Funding}

This work was supported by the Mexican National Council for Science and Technology (CONACYT), grant number 242065 of JMM.

\section{Availability of data and materials}

Data and materials are available with the corresponding author.

\section{Authors' contributions}

MSB and MAAG participated in the collection of data, manuscript drafting and saw and approved the final version. LRIR participated in data analysis and interpretation, manuscript editing and saw and approved the final version. JMM participated in the design of the study, data analysis and interpretation, manuscript editing and saw and approved the final version.

Ethics approval and consent to participate

All participants asked to fill written informed consent forms before study entrance. The study had been approved by local ethics committee of University of Guanajuato. 


\section{Consent for publication}

Not applicable.

\section{Competing interests}

The authors declare that they have no competing interests.

\section{Publisher's Note}

Springer Nature remains neutral with regard to jurisdictional claims in published maps and institutional affiliations.

\section{Author details}

'Department of Internal Medicine, Instituto Mexicano del Seguro Social, General Hospital Zone/MF 21, Leon, Guanajuato, Mexico. ${ }^{2}$ Department of Medical Sciences, University of Guanajuato, León Campus, León, GTO, Mexico. ${ }^{3}$ Department of General Surgery, Instituto Mexicano del Seguro Social, General Hospital Subzone No 10, Guanajuato, Guanajuato, Mexico.

Received: 14 June 2018 Accepted: 12 September 2018

Published online: 20 September 2018

\section{References}

1. Dalal PK, Agarwal M. Postmenopausal syndrome. Indian J Psychiatry. 2015; 57(suppl 2):222-32.

2. Jafari F, Hadizadeh MH, Zabihi R, et al. Comparison of depression, anxiety, quality of life, vitality and mental health between premenopausal and postmenopausal women. Climateric. 2014;17(6):660-5.

3. Aguilar-Zavala H, Pérez-Luque Elva L, Luna-Martínez F, et al. Symptoms at postmenopause: genetic and psychosocial factors. Menopause. 2012;19(10):1140-5.

4. Adibfar A, Saleem M, Lanctot KL, et al. Potential biomarkers for depression associated with coronary artery disease: a critical review. Curr Mol Med. 2016;16(2):137-64

5. Wong JM, Na B, Regan MC, et al. Hostility, health behaviors, and risk of recurrent events in patients with stable coronary heart disease: findings from the heart and soul study. J Am Heart Assoc. 2013;2(5):e000052.

6. Lloyd-Jones D, Adams RJ, Browm TM, et al. American Heart Association Statistics Committee and Stroke Statistics Subcommittee. Heart disease and stroke statistics-2010- update: a report from the American Heart Association. Circulation. 2010;121(7):e46-e215.

7. Sowers $\mathrm{M}$, Zheng $\mathrm{H}$, Tomey $\mathrm{K}$, et al. Changes in body composition in women over six years at midlife: ovarian and chronological aging. J Clin Endocrinol Metab. 2007:92(3):895-901.

8. Matthews $\mathrm{K}$, Meilahn $\mathrm{E}, \mathrm{Kuller} \mathrm{LH}$, et al. Menopause ad risk factors of coronary heart disease. N Engl J Med. 1989;321(10):641-6.

9. da Silva LH, Panazzolo DG, Marques MF, et al. Low-dose estradiol and endothelial and inflammatory biomarkers in menopausal overweight/obese women. Climateric. 2016;19(4):337-43.

10. Rossi R, Nuzzo A, Origliani G, et al. Prognosis role of flow-mediated dilation and cardiac risk factors in post-menopausal women. J Am Coll Cardiol. 2008;51(10):997-1002.

11. Santoro N, Sutton-Tyrrell K. The SWAN song: study of Women's health across the Nation's recurringthemes. Obstet Gynecol Clin N Am. 2011;38(3):417-23.

12. Agewall S. Is impaired flow-mediated dilatation of brachial artery a cardiovascular risk factor? Curr Vasc Pharmacol. 2003;1(2):107-9.

13. Benjamin EJ, Larson MG, Keyes MJ, et al. Clinical correlates and heritability of flow-mediated dilation in the community: the Framingham heart study. Circulation. 2004;109(5):613-9.

14. Lorenz MW, Markus HS, Bots M, et al. Prediction of clinical cardiovascular events with carotid intima-media thickness: a systematic review and metaanalysis. Circulation. 2007;115(4):459-67.

15. Santos-Garcia D, Rodriguez-Yañez M, Arias-Rivas $S$, et al. Brachial arterial flow mediated dilation: utility in clinical and experimental practice. Rev Neurol. 2011;53(6):351-60

16. Gurses KM, Tokgozoglu L, Yalcin MU, Kocyigit D, Dural M, Canpinar H, Yorgun H, Sahiner ML, Kaya EB, Akin S, Gurlek A, Guc D, Aytemir K. Markers of subclinical atherosclerosis in premenopausal women with vitamin D deficiency and effect of vitamin D replacement. Atherosclerosis. 2014:237(2):784-9.

17. Bechlioulis A, Kalantaridou SN, Naka KK, Chatzikyriakidou A, Calis KA, Makrigiannakis A, Papanikolaou O, Kaponis A, Katsouras C, Georgiou I, Chrousos GP, Michalis LK. Endothelial function, but not carotid intima-media thickness, is affected early in menopause and is associated with severity of hot flushes. J Clin Endocrinol Metab. 2010;95(3):1199-206.
18. Lambrinoudaki I, Kazani A, Armeni E, Rizos D, Augoulea A, Kaparos G, Alexandrou A, Georgiopoulos G, Kanakakis I, Stamatelopoulos K. The metabolic syndrome is associated with carotid atherosclerosis and arterial stiffness in asymptomatic, nondiabetic postmenopausal women. Gynecol Endocrinol. 2018;34(1):78-82.

19. Halaris A. Inflammation-associated co-morbidity between depression and cardiovascular disease. Curr Top Behav Neurosci. 2017;31:45-70.

20. Eller NH, Malmberg B, Bruhn P. Heart rate variability and intima media thickness. Int J Behav Med. 2006;13(3):201-13.

21. Sánchez-Barajas M, Figueroa-Vega N, Ibarra-Reynoso L, Del R, et al. Influence of heart rate variability and psychosocial factors on carotid stiffness, elasticity and impedance at menopause. Arch Med Res. 2015;46(2):118-26.

22. Soules MR, Sherman S, Parrott E, et al. Executive summary: stages of reproductive aging workshop (STRAW) Park City, Utah, July, 2001 Menopause. 2001:8(6):402-7.

23. García CR, Aguilar ZH, Malacara JM. Symptoms at menopause and care of grandchildren. Climateric. 2010;13(5):492-8.

24. Licht RW, Qvitzau S, Allerup P, et al. Validation of the Bech-Rafaelsen melancholia scale and the Hamilton depression scale in patients with major depression; is the total score a valid measure of illness severity? Acta Psychiatr Scand. 2005;111(2):144-9.

25. Garay-Sevilla ME, Malacara JM, González-Contreras E, et al. Perceived psychological stress in diabetes mellitus type 2. Rev Investig Clin. 2000; 52(3):240-5.

26. Cohen S, Kamarck T, Mermelstein R. A global measure of perceived stress. J Health Soc Behav. 1983;24(4):385-96.

27. Siegrist J. Adverse health effects of high-effort/low-reward conditions. J Occup Health Psychol. 1996;1(1):27-41.

28. Macías-Robles M, Fernández-López JA, Hernández-Mejía R, et al. Measuring psychosocial stress at work in Spanish hospital's personnel. Psychometric properties of the Spanish version of effort-reward imbalance model. Med Clin. 2003;120(17):652-7.

29. Allan S, Gilbert P. A social comparison scale: psychometric properties and relationship to psychopathology. Personal Individ Differ. 1995;19:293-9.

30. Heart rate variability. Standards of measurement, physiological interpretation and clinical use. Task force of the European Society of Cardiology and the north American Society of Pacing and Electrophysiology. Eur Heart J. 1996;17(3):354-81.

31. Perakakis P, Koffly M, Taylor M, et al. KARDIA: a Matlab software for the analysis of cardiac interbeat intervals. Comput Methods Prog Biomed. 2010;98(1):83-9.

32. Gamelin FX, Berthoin S, Baquet G. Validity of the polar $\mathrm{S} 810$ heart rate monitor to measure R-R intervals at rest. Med Sci Sports Exerc. 2006;38(5):887-93.

33. Gamelin FX, Baquet $\mathrm{G}$, Berthoin S, et al. Validity of the polar $\mathrm{S} 810$ to measure R-R intervals in children. Int J Sports Med. 2008;29(2):134-8.

34. Vanderlei LC, Silva RA, Pastre CM, et al. Comparison of the polar S810i monitor and the ECG for the analysis of heart rate variability in the time and frequency domains. Braz J Med Biol Res. 2008;41(10):854-9.

35. Corretti MC, Anderson TJ, Benjamin EJ, et al. Guidelines for the ultrasound assessment of endothelial-dependent flow-mediated vasodilation of the brachial artery: a report of the International Brachial Artery Reactivity Task Force. J Am Coll Cardiol. 2002;39(2):257-65.

36. Celermajer DS, Sorensen KE, Bull C, et al. Endothelium-dependent dilation in the systemic arteries of asymptomatic subjects relates to coronary risk factors and their interaction. J Am Coll Cardiol. 1994;24(6):1468-74.

37. Roman MJ, Naqvy TZ, Gardin JM, et al. American society of echocardiography report. Clinical application of noninvasive vascular ultrasound in cardiovascular risk stratification: a report from the American Society of Echocardiography and the society for vascular medicine and biology. Vasc Med. 2006;11(3):201-11.

38. Touboul PJ, Hennerici MG, Meairs S, et al. Mannheim carotid intima-media thickness consensus (2004-2006). Cerebrovasc Dis. 2007;23(1):75-80.

39. Nyberg $M$, Seidelin $K$, Andersen TR, et al. Biomarkers of vascular function in premenopausal and recent postmenopausal women of similar age: effect of exercise training. Am J Physiol Regul Integr Comp Physiol. 2014;306(7):R510-7.

40. Collins P, Webb CM, de Villiers TJ, et al. Cardiovascular risk assessment in women - an update. Climateric. 2016;19(4):329-36.

41. Maturana MA, Irigoyen MC, Spritzer PM. Menopause, estrogens, and endothelial dysfunction: current concepts. Clinics (Sao Paulo). 2007;62(1):77-86.

42. Moddithaya S, Avadhany ST. Comparison of cardiac autonomic activity between pre and postmenopausal women using heart rate variability. Indian J Physiol Pharmacol. 2009;53(3):227-34 
43. Gao L, Wu X, Zhu X, et al. Follicle-stimulating hormone associates with metabolic factors in postmenopausal women. Gynecol Endocrinol. 2018;27:1-4.

44. Virdis A, Ghiadoni L, Pinto S, et al. Mechanisms responsible for endothelial dysfunction associated with acute estrogen deprevation in normotensive women. Circulation. 2000;101(19):2258-63.

45. Augustine AL, Lefferts WK, Dowthwaite JN, et al. Subclinical atherosclerosis risk in endurance-trained premenopausal amenorrheic women. Atherosclerosis. 2016;244:157-64.

46. Jarpa C, Pineda V, Manterola C. Thickness of carotid intima-media as a predictor of cardiovascular events. Systematic review of the literature. Int J Morphol. 2013;31(1):293-300.

47. Kotsis VT, Stabouli SV, Papamichael CM, et al. Impact of obesity in intima media thickness of carotid arteries. Obesity (Silver Spring). 2006;14(10):1708-15.

48. Koskinen J, Kähönen M, Viikari JS, et al. Conventional cardiovascular risk factors and metabolic syndrome in predicting carotid intima-media thickness progression in young adults: the cardiovascular risk in young Finns study. Circulation. 2009;120(3):229-36.

49. Maher V, O'Dowd M, Carey M, et al. Association of central obesity with early carotid intima-media thickening is independent of that from other risk factors. Int J Obes. 2009;33(1):136-43.

50. Dalmas E, Kahn JF, Giral P, et al. Intima-media thickness in severe obesity: links with BMI and metabolic status but not with systemic or adipose tissue inflammation. Diabetes Care. 2013;36(11):3793-802.

51. Shively CA, Clakson TB. Social status and coronary artery atherosclerosis in female monkeys. Arterioscler Thromb. 1994;14(5):721-6.

52. Varleta P. Concepción $R$, Vargas $P$, et al. Association of carotid intima-media thickness with traditional cardiovascular risk and metabolic factors. Rev Med Chil. 2013;141(6):695-703.

53. Do KA, Green A, Guthrie JR, et al. Longitudinal study of risk factors for coronary heart disease across the menopausal transition. Am J Epidemiol. 2000;151(6):584-93.

Ready to submit your research? Choose BMC and benefit from:

- fast, convenient online submission

- thorough peer review by experienced researchers in your field

- rapid publication on acceptance

- support for research data, including large and complex data types

- gold Open Access which fosters wider collaboration and increased citations

- maximum visibility for your research: over $100 \mathrm{M}$ website views per year

At BMC, research is always in progress.

Learn more biomedcentral.com/submissions 